\title{
Utilização de Subprodutos de Origem Animal em Dietas Formuladas com Base em Proteína Bruta e Proteína Ideal para Frangos de Corte de 22 a 42 Dias de Idade ${ }^{1}$
}

\section{Luciana Cardoso Cancherini ${ }^{2}$, Otto Mack Junqueira ${ }^{3}$, Maria Cristina de Oliveira ${ }^{4}$, Marcelo de Oliveira Andreotti $i^{5}$, Maria José Baptista Barbosa ${ }^{6}$}

\begin{abstract}
RESUMO - Foi conduzido um experimento para avaliar a utilização de subprodutos de origem animal em dietas para frangos de corte de 22 a 42 dias de idade, formuladas com base nos conceitos de proteína bruta e proteína ideal. O delineamento foi inteiramente casualizado em esquema fatorial $2 \times 2+1$, ou seja, duas fontes de proteína de origem animal (farinha de vísceras de aves e farinha de sangue bovino), dois conceitos de formulação (proteína bruta e proteína ideal) e uma dieta controle à base de milho e farelo de soja, com quatro repetições. As características avaliadas foram ganho de peso, consumo de ração, conversão alimentar, rendimentos de carcaça e de peito e gordura abdominal. O ganho de peso, consumo de ração e conversão alimentar não foram afetados pelas fontes de proteína e conceitos de formulação, no entanto, o teor de gordura abdominal foi menor nas aves alimentadas com farinha de vísceras que naquelas alimentadas com dieta contendo farinha de sangue.
\end{abstract}

Palavras-chave: frangos de corte, nutrição animal, proteína ideal, subprodutos

\section{Use of Animal By-Products in Diets Formulated Based on Crude and Ideal Protein Fed to Broilers from 22 to 42 Days of Age}

\begin{abstract}
An experiment was conducted to evaluate the use of animal by-products in diets of broilers from 22 to 42 days of age, formulated based on crude and ideal protein concepts. The experimental design was a completely randomized in a factorial arrangement $2 \times 2+1$ with two animal protein sources (poultry viscera meal and bovine blood meal), two formulation concepts (based on crude and ideal protein) and a control diet based on corn and soybean meal, with four replications. The evaluated characteristics were weight gain, feed intake, feed: gain ratio, carcass and breast yield and abdominal fat content. Weight gain, feed intake and feed: gain ratio were not affected by the protein sources and formulation concepts, however, abdominal fat content of broilers fed diets with poultry viscera meal was lower compared to birds that fed diets containing bovine blood meal.
\end{abstract}

Key Words: animal nutrition, broilers, by-products, ideal protein

\section{Introdução}

A proteína é um dos componentes mais caros da dieta de frangos de corte e pode afetar o desempenho, além dos custos do produto final. Durante muitos anos, a formulação de rações para aves esteve baseada na proteína bruta, resultando em rações com conteúdo de aminoácidos superior aos requerimentos dos animais. Com a disponibilidade econômica dos aminoácidos industriais, as dietas passaram a ser formuladas com níveis inferiores de proteína e níveis de aminoácidos mais próximos das necessidades do animal, mantendo, porém, níveis de proteína excessivamente altos. O conceito de proteína ideal torna-se mais interessante quando se consideram ingredientes usados com menos freqüência, como os subprodutos de origem animal.

Deve-se considerar que os requerimentos de aminoácidos são baseados nos níveis de aminoácidos totais dosalimentos. Entretanto, as quantidades destes aminoácidos contidas nos ingredientes das dietas são muito maiores que as quantidades digestíveis (Wang \& Parsons, 1998).

O teor de proteína bruta e de aminoácidos essenciais de uma dieta influencia a composição da carcaça de frangos. Alto teor de proteína bruta promove aumento no teor de proteína e reduz o teor de gordura na carcaça, ao passo que frangos alimentados com dietas marginais em aminoácidos consumirão mais para alcançar seus requerimentos para ganho de peso (Leeson, 1995; Si et al., 2001).

\footnotetext{
1 Parte da Dissertação do primeiro autor, apresentada à FCAV/UNESP, Jaboticabal, SP. Pesquisa financiada pela FAPESP

2 Profa do Dep. de Zootecnia da Universidade do Estado de Mato Grosso - Unemat/MT. E.mail: lucianac@fcav.unesp.br

3 Prof. Titular do Dep. de Zootecnia, FCAV/UNESP. E.mail: ottomack@fcav.unesp.br

${ }^{4}$ Profa. Adj. do Dep. de Zootecnia, FESURV, Rio Verde, GO. E.mail: cristina@fesurv.br

5 Prof. do DPL/CCBS da Universidade Federal do Mato Grosso do Sul UFMS/MS.

${ }^{6}$ Profa do Dep. de Zootecnia da Universidade Estadual de Maringá - PR.
} 
Stringhini et al. (1997ab) verificaram os efeitos dos níveis de proteína nas dietas $(22,20$ e 19\% proteína bruta) sobre o desempenho e as características de carcaça de frangos de corte criados em densidades de 12 e 18 aves $/ \mathrm{m}^{2}$ e observaram que o aumento dos níveis de proteína nas dietas foi eficiente em reduzir os níveis de gordura abdominal para as densidades populacionais testadas, no entanto, não foram observadas diferenças significativas para os índices de desempenho. Com o objetivo de avaliar o efeito de dietas contendo diferentes níveis de proteína (18 a 22\%) sobre o desempenho de frangos de corte criados sob alta temperatura ambiente $\left(34^{\circ} \mathrm{C}\right)$, Rostagno (1997) observou que o nível protéico das dietas de frangos de corte pode ser reduzido pela suplementação de aminoácidos industriais sem afetar o desempenho e a qualidade da carcaça das aves.

Dietas contendo baixo teor de proteína bruta $(16,53 \%)$ resultaram em pior desempenho que aquelas com alto teor de proteína bruta $(21,47 \%)$, independentemente da suplementação com níveis adequados de aminoácidos essenciais (Ferguson et al., 1998a). Ferguson et al. (1998b) observaram que não houve diferenças quanto ao ganho de peso, consumo de ração e conversão alimentar em frangos alimentados com dietas contendo 20,60 e 18,20\% de proteína bruta (suplementadas com aminoácidos industriais).

Segundo Rostagno et al. (1995), os ingredientes alternativos, sobretudo os de origem animal, têm grande variação na sua composição química, conforme a matéria-prima utilizada e o processamento empregado. Portanto, o uso de dados errados de disponibilidade de aminoácido pode acarretar piora no desempenho das aves. Alguns estudos têm sido conduzidos com a finalidade de utilizar a grande quantidade de proteína animal desperdiçada nos abatedouros. Segundo Leeson $\&$ Summers (1997), a farinha de sangue é um alimento com alto teor de proteína bruta, mas é menos digestível e de qualidade inferior à farinha de carne e ossos. A farinha de sangue, quando bem processada, possui elevados teores de lisina, o que a torna um alimento bastante útil. Por outro lado, é pobre em isoleucina, devendo o equilíbrio deste aminoácido ser considerado quando são utilizados níveis elevados deste produto nas rações.

Objetivou-se, com este trabalho, avaliar a utilização dos subprodutos de origem animal (farinha de vísceras e sangue) em dietas para frangos de corte, formuladas com base no conceito de proteína bruta e proteína ideal.

\section{Material e Métodos}

O experimento foi conduzido no mês de março de 2000, utilizando-se 600 frangos machos de 22 dias de idade, da linhagem comercial Ross, com peso médio inicial de 930,50 g. As aves foram manejadas conforme Gomes et al. (1996) de 1 até 21 dias de idade e, após este período, foram pesadas e distribuídas em boxes, equipados com bebedouro pendular e comedouro tubular e, durante todo o período experimental, tiveram livre acesso à água e à ração. $\mathrm{O}$ material utilizado como cama foi o cepilho de madeira com espessura de aproximadamente $8 \mathrm{~cm}$.

O delineamento experimental empregado foi inteiramente casualizado, em esquema fatorial $2 \times 2+1$, com dois conceitos de formulação (proteína bruta e ideal), duas fontes de proteína de origem animal (farinha de vísceras de aves e farinha de sangue bovino) e uma dieta testemunha à base de milho e farelo de soja (MFS) formulada com base na proteína bruta, totalizando cinco tratamentos (T), com quatro repetições. Os tratamentos foram os seguintes: $\mathrm{T}_{1}=$ MFS com base na proteína bruta $(\mathrm{PB})$ (ração controle); $\mathrm{T}_{2}=\mathrm{MFS}+$ farinha de vísceras (FV) com base na PB; $\mathrm{T}_{3}=\mathrm{MFS}+\mathrm{FV}$ com base na proteína ideal (PI); $\mathrm{T}_{4}=\mathrm{MFS}+$ farinha de sangue (FSG) com base na PB; e $\mathrm{T}_{5}=$ MFS + FSG com base na PI. O nível de inclusão dos subprodutos foi de $6 \%$ em todas as rações.

As rações experimentais foram formuladas segundo as recomendações nutricionais do NRC (1994), para proteína bruta e aminoácidos totais e de Rostagno et al. (1996), para os aminoácidos digestíveis (Tabela 1). Nas formulações com base na proteína ideal, foi mantida a relação lisina:metionina+cistina igual a 100:78.

As características avaliadas foram o consumo de ração, o ganho de peso, a conversão alimentar, os rendimentos de carcaça e de peito e a porcentagem de gordura abdominal. Ao fim do período experimental (42 dias de idade), após as pesagens, foram separadas três aves por box representantes do peso corporal médio da respectiva parcela (5\% acima e abaixo da média). Estas aves foram abatidas por sangria na artéria jugular após jejum de seis horas e, após sangramento e depenação, foram evisceradas, tendo suas carcaças (sem cabeça + pescoço, pé e gordura abdominal) pesadas em balança digital. Assim que os frangos foram eviscerados, procedeu-se à retirada da gordura abdominal, que também foi pesada. Na determinação do rendimento de carcaça, foi considerado o peso da carcaça limpa e eviscerada e o peso vivo após jejum, obtido antes do abate. $\mathrm{O}$ rendimento do peito e o peso 
Tabela 1 - Composição das dietas utilizadas de 22 a 42 dias de idade

Table 1 - Composition of the diets used from 22 to 42 days of age

\begin{tabular}{|c|c|c|c|c|c|}
\hline \multirow{3}{*}{$\begin{array}{l}\text { Ingrediente }(\mathrm{kg}) \\
\text { Ingredient }(\mathrm{kg})\end{array}$} & \multirow[b]{2}{*}{ MFS } & \multicolumn{2}{|c|}{$\begin{array}{l}\mathrm{FV} \\
V M\end{array}$} & \multicolumn{2}{|c|}{$\begin{array}{l}\text { FSG } \\
B M\end{array}$} \\
\hline & & PB & $\mathrm{PI}^{1}$ & PB & $\mathrm{PI}^{1}$ \\
\hline & $C S M$ & $C P$ & $I P^{l}$ & $C P$ & $I P^{l}$ \\
\hline Milho moído & 58,64 & 63,06 & 61,55 & 64,95 & 70,60 \\
\hline $\begin{array}{l}\text { Ground corn } \\
\text { Farelo de soja } \\
\text { Soybean meal }\end{array}$ & 32,92 & 24,95 & 26,20 & 21,10 & 16,26 \\
\hline $\begin{array}{l}\text { Óleo de soja } \\
\text { Soybean oil }\end{array}$ & 4,94 & 2,90 & 3,12 & 4,26 & 3,25 \\
\hline $\begin{array}{l}\text { Fosfato bicálcico } \\
\text { Dicalcium phosphate }\end{array}$ & 1,50 & 1,30 & 1,28 & 1,79 & 1,87 \\
\hline $\begin{array}{l}\text { Calcário calcítico } \\
\text { Limestone }\end{array}$ & 1,10 & 0,95 & 0,95 & 1,00 & 1,00 \\
\hline $\begin{array}{l}\text { Sal comum } \\
\text { Salt }\end{array}$ & 0,33 & 0,31 & 0,30 & 0,31 & 0,32 \\
\hline $\begin{array}{l}\text { Suplemento mineral + vitamínico } \\
\text { Mineral + vitamin supplement }{ }^{2}\end{array}$ & 0,50 & 0,50 & 0,50 & 0,50 & 0,50 \\
\hline $\begin{array}{l}\text { DL-metionina } 99 \% \\
\text { DL-methionine } 99 \%\end{array}$ & 0,07 & 0,03 & 0,10 & 0,09 & 0,20 \\
\hline $\begin{array}{l}\text { Farinha de vísceras de aves } \\
\text { Poultry viscera meal }\end{array}$ & - & 6,00 & 6,00 & - & - \\
\hline $\begin{array}{l}\text { Farinha de sangue bovino } \\
\text { Bovine blood meal }\end{array}$ & - & - & - & 6,00 & 6,00 \\
\hline Total (Total) & 100 & 100 & 100 & 100 & 100 \\
\hline \multicolumn{6}{|c|}{ Composição calculada (Calculated composition) ${ }^{3}$} \\
\hline $\begin{array}{l}\text { Energia metabolizável }(\mathrm{kcal} / \mathrm{kg}) \\
\text { Metabolizable energy }(\mathrm{kcal} / \mathrm{kg})\end{array}$ & 3200 & 3200 & 3200 & 3200 & 3200 \\
\hline $\begin{array}{l}\text { Proteína bruta }(\%) \\
\text { Crude protein }(\%)\end{array}$ & 20,000 & 20,160 & 20,590 & 20,000 & 18,280 \\
\hline $\begin{array}{l}\text { Extrato etéreo }(\%) \\
\text { Ether extract }(\%)\end{array}$ & 7,370 & 6,089 & 6,270 & 6,780 & 5,900 \\
\hline $\begin{array}{l}\text { Lisina }(\%) \\
\text { Lysine (\%) }\end{array}$ & 1,057 & 1,000 & 1,031 & 1,154 & 1,032 \\
\hline $\begin{array}{l}\text { Lisina digestível (\%) } \\
\text { Digestible lysine (\%) }\end{array}$ & 0,951 & 0,884 & 0,912 & 1,022 & 0,912 \\
\hline $\begin{array}{l}\text { Metionina + cistina }(\%) \\
\text { Methionine + cystine }(\%)\end{array}$ & 0,720 & 0,720 & 0,809 & 0,720 & 0,782 \\
\hline $\begin{array}{l}\text { Metionina + cistina digestível (\%) } \\
\text { Digestible methionine + cystine (\%) }\end{array}$ & 0,646 & 0,624 & 0,711 & 0,644 & 0,711 \\
\hline $\begin{array}{l}\text { Fósforo disponível (\%) } \\
\text { Available phosphorus (\%) }\end{array}$ & 0,387 & 0,494 & 0,492 & 0,434 & 0,446 \\
\hline $\begin{array}{l}\text { Cálcio }(\%) \\
\text { Calcium }(\%)\end{array}$ & 0,900 & 0,900 & 0,900 & 0,900 & 0,900 \\
\hline
\end{tabular}

1 Relação lisina:aminoácido (Lysine: amino acid ratio) 0,912 (100\%); met+cist (met+cys) 0,711 (78\%).

2 Suplemento mineral e vitamínico (Mineral and vitamin supplement). Enriquecimento/kg de ração (Enrichment/kg of ration): Vit. A (Vitamin A) 1500 $\mathrm{UI} / \mathrm{kg}$, Vit. $\mathrm{D}_{3}\left(\right.$ Vitamin $\left.D_{3}\right) 500 \mathrm{UI} / \mathrm{kg}$, Vit. E (Vitamin E) $20 \mathrm{mg}$, Vit. $\mathrm{K}_{3}\left(\right.$ Vitamin $\left.K_{3}\right) 0,5 \mathrm{mg}$, Vit. $\mathrm{B}_{1}\left(\right.$ Vitamin $\left.B_{1}\right) 2 \mathrm{mg}$, Vit. $\mathrm{B}_{2}\left(\right.$ Vitamin $\left.B_{2}\right) 3,6 \mathrm{mg}$, Vit. $B_{12}$ (Vitamin $\left.B_{12}\right) 20 \mathrm{mcg}$, pantotenato de cálcio (calcium pantothenic) $10 \mathrm{mg}$, ácido fólico (folic acid) 0,5 mg, promotor de crescimento (growth promoter) $50 \mathrm{mg}$, niacina (niacine) $100 \mathrm{mg}, \mathrm{Cu} 75 \mathrm{mg}, \mathrm{I} 1,25 \mathrm{mg}$, Se 0,25 mg, Mn $120 \mathrm{mg}$, Zn $100 \mathrm{mg}$, Fe 50 mg, antioxidante (antioxidant) $0,5 \mathrm{mg}$, coccidicida (coccidicide) $110 \mathrm{mg}$.

3 De acordo com (According to) Rostagno et al. (2000).

relativo da gordura abdominal foram calculados em relação ao peso da carcaça eviscerada. Considerou-se como gordura abdominal aquela depositada na região abdominal, próxima à Bursa de Fabricius e a gordura aderida à moela e ao proventrículo.
Os dados obtidos foram submetidos à análise estatística, por meio do programa "ESTAT", desenvolvido pelo Departamento de Ciência Exatas da FCAV-UNESP Jaboticabal, e as médias foram comparadas pelo teste Tukey. 


\section{Resultados e Discussão}

Não foi significativo o efeito da interação entre os fatores fontes de proteína animal e conceitos de formulação (Tabela 2) para as características consumo de ração, ganho de peso e conversão alimentar. Portanto, pode-se inferir que os fatores formulação da ração (proteína bruta ou ideal) e subprodutos atuam independentemente e que tanto a farinha de vísceras quanto a de sangue atendem adequadamente os requerimentos nutricionais das aves.

Os valores obtidos discordam dos encontrados por Dari \& Penz Jr. (1996), que avaliaram o desempenho de frangos de 21 a 42 dias de idade alimentados com dietas contendo ingredientes de baixa digestibilidade (6,5\% farelo de trigo, $5 \%$ de farinha de carne e ossos e $5 \%$ de farinha de penas, calculados com base em aminoácidos total e digestível) e observaram superioridade das rações formuladas com base em aminoácido digestível.

Não foram verificadas interações entre fontes de proteína animal e conceito de formulação para rendimento de carcaça e de peito e porcentagem de gordura abdominal (Tabela 3), mas o peso relativo da gordura abdominal foi significativamente maior $(\mathrm{P}<0,05)$ nas aves alimentadas com dietas contendo farinha de sangue que naquelas que ingeriram farinha de vísceras, o que deve ter ocorrido em razão de as dietas contendo farinha de sangue apresentarem maiores conteúdos em óleo vegetal adicionado e, possivelmente, conteúdo em extrato etéreo.

Apesar de não ter ocorrido diferença estatisticamente significativa, as aves alimentadas com a ração testemunha, à base de milho e farelo de soja, apresentaram porcentagem de gordura abdominal numericamente menor que aquelas que consumiram dietas com fontes de proteína de origem animal. Esta variação numérica entre os tratamentos pode ser explicada, em parte, pelo trabalho de Leeson (1995), que relata que, além da energia fornecida pela dieta, esta variação também pode ser decorrente da desaminação de proteínas e, portanto, o fornecimento de proteína bruta em excesso ou de qualidade inferior, sem um bom equilíbrio de aminoácidos, poderá implicar em maior potencial para deposição de gordura. Portanto, maximizar a deposição de proteínas na ave depende

Tabela 2 - Resultados de desempenho de frangos de corte de 22 a 42 dias de idade

Table 2 - Performance results of broilers from 22 to 42 days of age

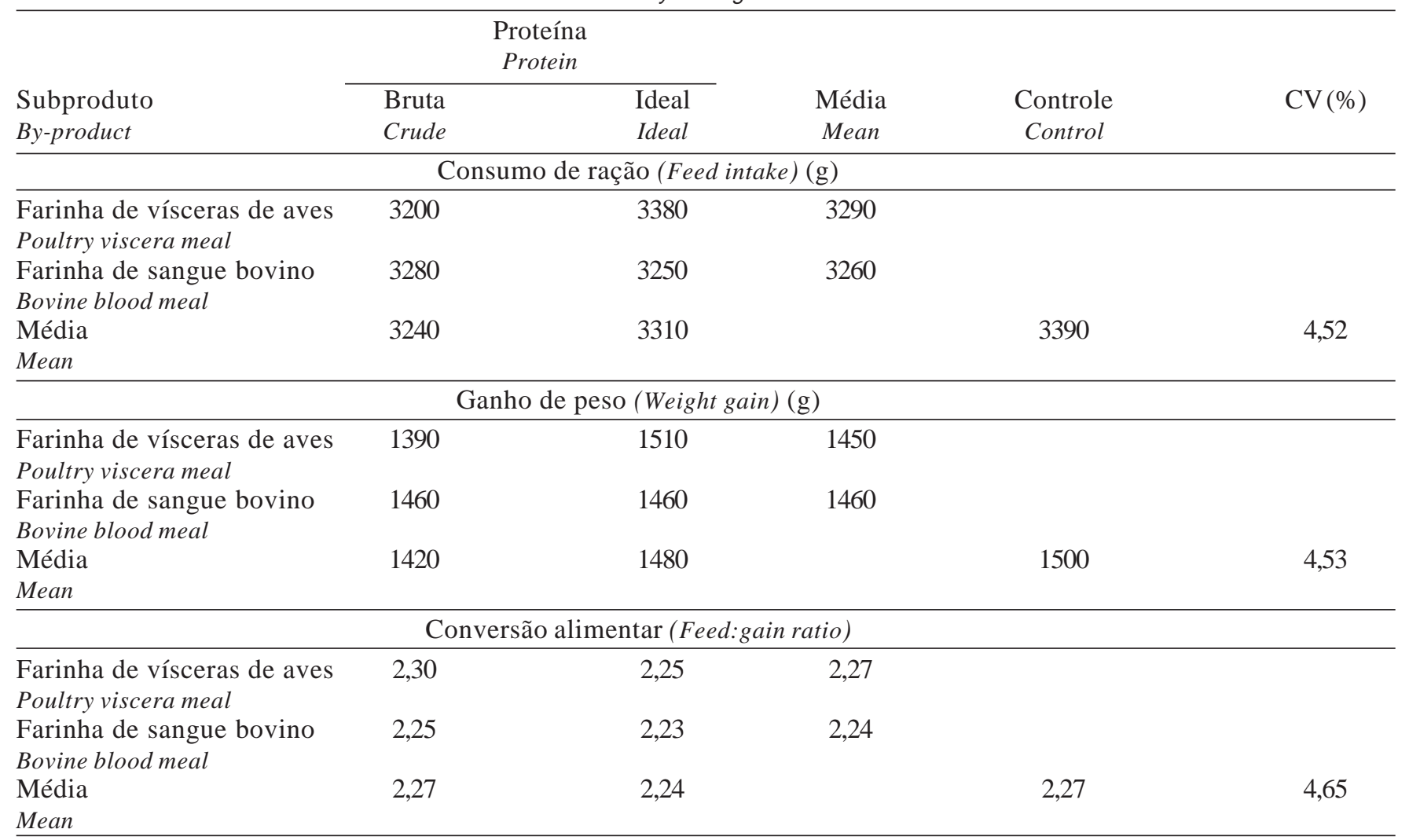

Coeficiente de variação (Coefficient of variation). 
Tabela 3 - Rendimentos de carcaça e de peito e teor gordura abdominal de frangos de corte de 22 a 42 dias de idade Table 3 - Carcass and breast yield and abdominal fat content of broilers from 22 to 42 days of age

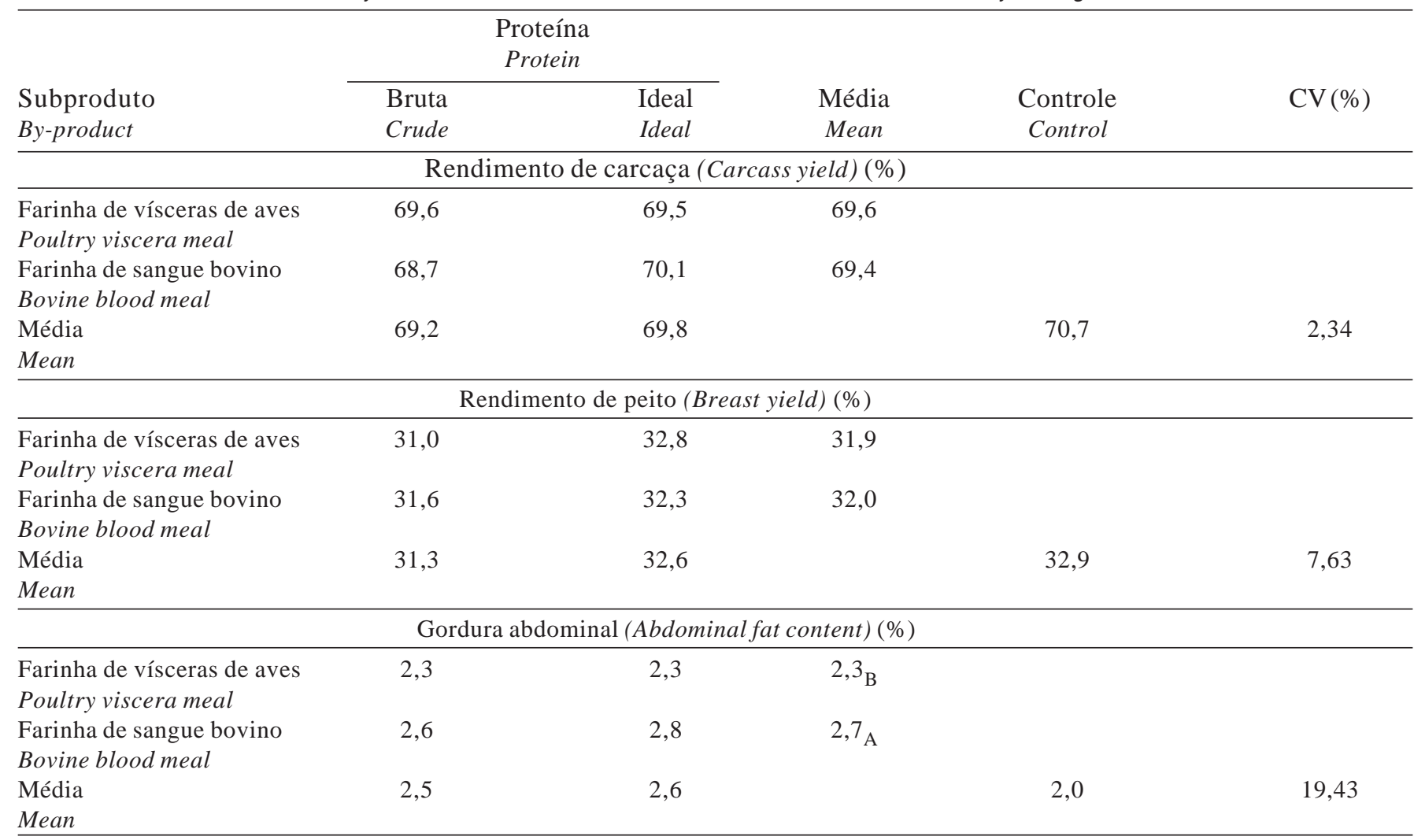

Coeficiente de variação (Coefficient of variation).

Médias seguidas de letras distintas diferem $(P<0,05)$ entre si pelo teste Tukey.

Means followed by different letters differ $(P<.05)$ by Tukey test.

de atingir as exigências diárias de proteína, necessárias para a síntese de proteínas, ao mesmo tempo que minimizar a deposição de gorduras depende de evitar a ingestão excessiva de energia em relação à necessidade para manutenção e crescimento.

\section{Conclusões}

Ambas as farinhas de vísceras de aves e de sangue bovino podem ser utilizadas na ração de frangos de corte, independemente se as dietas são baseadas em proteína bruta ou proteína ideal, mas deve-se considerar que a adição de farinha de sangue bovino promove aumento do teor de gordura na carcaça.

\section{Literatura Citada}

DARI, R.L.; PENZ JR., A.M. The use of digestible amino acid and ideal protein concept in diet forumlation for broilers. In: ANNUAL MEETING OF POULTRY SCIENCE ASSOCIATION, 85., 1996, Louisville. Proceedings... Louisville: PSA, 1996. p.67.
ESTAT. Sistema para análise estatística. Departamento de exatas. FCAV/UNESP. Jaboticabal-SP versão 4.03.

FERGUSON; N.S.; GATES, R.S.; TARABA, J.L. et al. The effect of dietary crude protein on growth, ammonia concentration, and litter composition in broilers. Poultry Science, v.77, n.10, p.1481-1487, 1998a.

FERGUSON, N.S.; GATES, R.S.; TARABA, J.L. et al. The effect of dietary protein and phosphorus on ammonia concentration and litter composition in broilers. Poultry Science, n.77, v.8, p.1085-1093, 1998b.

GOMES, P.C.; ALBINO, L.F.T.; SILVA, M.A. Criação de frangos de corte. Informe técnico. Viçosa, MG. Ano $17 \mathrm{n}^{\circ} 78$, 1996. $18 \mathrm{p}$.

LEESON, S. Nutrição e qualidade de carcaça de frangos de corte. In: COFERÊNCIA APINCO DE CIÊNCIA E TECNOLOGIA AVÍCOLAS, 1995, Curitiba. Anais... Campinas: FACTA, 1995. p.111-118.

LEESON, S.; SUMMERS, J. D. Commercial poultry nutrition. 2.ed. Guelph: University of Guelph Press, 1997. 350p.

NATIONAL RESEARCH COUNCIL - NRC. Nutrients requeriments of poultry. 9.ed. Washington, D.C.: National Academy Press, 1994. 155p.

ROSTAGNO, H.S.; PUPA, J.M.R.; PACK, M. Diet formulation for broilers based on total versus digestible amino acid. Journal of Applied Poultry Research, v.4, p.293-9, 1995. 
ROSTAGNO, H.S.; BARBARINO JR.P.; BARBOZA, W.A. Exigências nutricionais das aves determinadas no Brasil. In: SIMPÓSIO INTERNACIONAL SOBRE EXIGÊNCIAS NUTRICIONAIS DE AVES E SUÍNOS, 1996, Viçosa, MG. Anais...Viçosa, MG: Universidade Federal de Viçosa, 1996. p.326-88.

ROSTAGNO, H.S. Rações com diferentes níveis de proteína para frangos de corte. In: ENCONTRO DE NUTRIÇÃO ANIMAL, 3., 1997, São Paulo. Anais... São Paulo: Degussa Finnfeeds, 1997. 10p.

ROSTAGNO, H.S.; ALBINO, L.F.T.; DONZELE, J.L. et al. Tabelas brasileiras para aves e suínos - composição de alimentos e exigências nutricionais. Viçosa, MG: Universidade Federal de Viçosa, 2000. 141p.

SI, J.; FRITTS, C.A.; BURNHAM, D.J. et al. Relationship of dietary lysine level to the concentration of all essential amino acids in broiler diets. Poultry Science, v.80, n.10, p.1472-1479, 2001.
STRINGHINI, H.; ARIKI, J.; CAFÉ, M.B. et al. Níveis de proteína para frangos de corte criados em duas densidades populacionais. II. Desempenho. In: CONFERÊNCIA APINCO DE CIÊNCIA E TECNOLOGIA AVÍCOLAS. 1997, São Paulo. Anais... Campinas: FACTA, 1997a. p.25. STRINGHINI, H.; ARIKI, J.; CAFÉ, M.B. et al. Níveis de proteína para frangos de corte criados em duas densidades populacionais. II. Características de carcaça. In: CONFERÊNCIA APINCO DE CIÊNCIA E TECNOLOGIA AVÍCOLAS. 1997, São Paulo. Anais... Campinas: FACTA, 1997b. p. 24.

WANG, X.; PARSONS, C.M. Dietary formulation with meat and bone meal on a total versus a digestible or bioavailable amino acid basis. Poultry Science, v.77, n.7, p.1010-1015, 1998.

Recebido em: 13/22/04

Aceito em: 23/01/05 